\title{
Satisfaction Attainment THeORY as a Model for Value Creation
}

\section{R.O. Briggs, S. Qureshi and B. Reining}

\begin{tabular}{|l|l|}
\hline \multicolumn{2}{|l|}{ ERIM REPORT SERIES RESEARCH IN MANAGEMENT } \\
\hline ERIM Report Series reference number & ERS-2004-062-LIS \\
\hline Publication & June 2004 \\
\hline Number of pages & 10 \\
\hline Email address corresponding author & squreshi@ist.unomaha.edu \\
\hline Address & Erasmus Research Institute of Management (ERIM) \\
& Rotterdam School of Management / Rotterdam School of \\
& Economics \\
& Erasmus Universiteit Rotterdam \\
& P.O. Box 1738 \\
& 3000 DR Rotterdam, The Netherlands \\
& Phone: +31 10 408 1182 \\
& Fax: +31 10 408 9640 \\
& Email: info@erim.eur.nl \\
& Internet: www.erim.eur.nl \\
\hline
\end{tabular}

Bibliographic data and classifications of all the ERIM reports are also available on the ERIM website: www.erim.eur.nl 


\title{
ERASMUS RESEARCH INSTITUTE OF MANAGEMENT
}

\author{
REPORT SERIES \\ RESEARCH IN MANAGEMENT
}

\begin{tabular}{|c|c|c|}
\hline \multicolumn{3}{|c|}{ BIBLIOGRAPHIC DATA AND CLASSIFICATIONS } \\
\hline Abstract & \multicolumn{2}{|c|}{$\begin{array}{l}\text { Organizations exist to create value for their stakeholders that stakeholders cannot create } \\
\text { through individual effort. Information systems exist to increase an organization's ability to create } \\
\text { value using intellectual capital. A theoretical explanation of value might therefore be useful to } \\
\text { increase the likelihood that IS/IT professionals would design and deploy systems in ways that } \\
\text { increase value for stakeholders. This paper proposes Satisfaction Attainment Theory (SAT) as } \\
\text { causal model of value creation. An organizational stakeholder is a person whose wellbeing } \\
\text { might be advanced by an organization. Perceptions of value have reference to some object-of- } \\
\text { value. The term, object, in the context of this paper, means anything to which one could ascribe } \\
\text { value - e.g. goods, services, states, or outcomes. SAT assumes that people hold multiple, } \\
\text { conflicting goals, and so must sacrifice the yield of some goal to attain others. It posits that an } \\
\text { individual automatically and subconsciously sets an expectation for some level of utility from } \\
\text { attaining a goal and assesses the likelihood that a goal will be attained. It also posits that } \\
\text { individuals automatically and subconsciously assess yield the yield of a Set of Salient Goals } \\
\text { (SSG). Any perceived Shift in the Yield Assessment (SYA) for the salient set of goals is } \\
\text { automatically accompanied by an affective arousal proportional to and with a valence in the } \\
\text { direction of the perceived SYA. SAT proposes that the value of an object is a positive function of } \\
\text { the SYA that occurs when an individual contemplates sacrificing the yield of other goals to obtain } \\
\text { the yield that could be derived from the object. Value is therefore created by making an } \\
\text { individual aware of an opportunity to attain a positive SYA by sacrificing the yield of one set of } \\
\text { goals to attain the yield of another set }\end{array}$} \\
\hline \multirow{3}{*}{$\begin{array}{l}\text { Library of Congress } \\
\text { Classification } \\
\text { (LCC) }\end{array}$} & $5001-6182$ & Business \\
\hline & $5201-5982$ & Business Science \\
\hline & HD 30.28 & Strategic Management \\
\hline \multirow{4}{*}{$\begin{array}{l}\text { Journal of Economic } \\
\text { Literature } \\
\text { (JEL) }\end{array}$} & M & Business Administration and Business Economics \\
\hline & M 11 & Production Management \\
\hline & R 4 & Transportation Systems \\
\hline & D 29 & Production and Organization, other \\
\hline \multirow{4}{*}{$\begin{array}{l}\text { European Business Schools } \\
\text { Library Group } \\
\text { (EBSLG) }\end{array}$} & $85 \mathrm{~A}$ & Business General \\
\hline & $260 \mathrm{~K}$ & Logistics \\
\hline & $240 \mathrm{~B}$ & Information Systems Management \\
\hline & $270 \mathrm{~A}$ & Strategic Management \\
\hline \multicolumn{3}{|c|}{ Gemeenschappelijke Onderwerpsontsluiting (GOO) } \\
\hline \multirow[t]{4}{*}{ Classification GOO } & 85.00 & Bedrijfskunde, Organisatiekunde: algemeen \\
\hline & 85.34 & Logistiek management \\
\hline & 85.20 & Bestuurlijke informatie, informatieverzorging \\
\hline & 85.10 & Strategisch beleid \\
\hline \multirow[t]{3}{*}{ Keywords GOO } & \multicolumn{2}{|c|}{ Bedrijfskunde / Bedrijfseconomie } \\
\hline & \multicolumn{2}{|c|}{ Bedrijfsprocessen, logistiek, management informatiesystemen } \\
\hline & \multicolumn{2}{|c|}{ Toegevoegde waarde, waardebepaling } \\
\hline Free keywords & \multicolumn{2}{|c|}{$\begin{array}{l}\text { value creation, satisfaction attainment theory (SAT), goal assessment, yield assessment, } \\
\text { affective response, Shift in the Yield Assessment (SYA) }\end{array}$} \\
\hline
\end{tabular}


In: the Hawaii linterbational Conference on Systems Sciences, IEEE. 2004

\section{Satisfaction Attainment Theory as a Model for Value Creation}

\author{
Robert O. Briggs \\ Faculty of Technology, \\ Policy, and Management \\ Delft University of \\ Technology \\ The Netherlands \\ CMI, University of Arizona \\ USA 85721 \\ bbriggs@groupsystems.com
}

\author{
Sajda Qureshi \\ Department of Information \\ Systems and Quantitative \\ Analysis \\ College of Information Science \\ and Technology \\ University of Nebraska at \\ Omaha \\ Omaha, NE 68182-0392 \\ squreshi@ist.unomaha.edu
}

\author{
Bruce Reinig \\ Department of Information \\ and Decision Systems \\ College of Business \\ Administration \\ San Diego State University \\ San Diego CA 92182 \\ breinig@mail.sdsu.edu
}

\begin{abstract}
Organizations exist to create value for their stakeholders that stakeholders cannot create through individual effort. Information systems exist to increase an organization's ability to create value using intellectual capital. A theoretical explanation of value might therefore be useful to increase the likelihood that IS/IT professionals would design and deploy systems in ways that increase value for stakeholders. This paper proposes Satisfaction Attainment Theory (SAT) as causal model of value creation. An organizational stakeholder is a person whose wellbeing might be advanced by an organization. Perceptions of value have reference to some object-of-value. The term, object, in the context of this paper, means anything to which one could ascribe value - e.g. goods, services, states, or outcomes. SAT assumes that people hold multiple, conflicting goals, and so must sacrifice the yield of some goal to attain others. It posits that an individual automatically and subconsciously sets an expectation for some level of utility from attaining a goal and assesses the likelihood that a goal will be attained. It also posits that individuals automatically and subconsciously assess yield the yield of a Set of Salient Goals (SSG). Any perceived Shift in the Yield Assessment (SYA) for the salient set of goals is automatically accompanied by an affective arousal proportional to and with a valence in the direction of the perceived SYA. SAT proposes that the value of an object is a positive function of the SYA that occurs when an individual contemplates sacrificing the yield of other goals to obtain the yield that could be derived from the object. Value is therefore created by making
\end{abstract}

an individual aware of an opportunity to attain a positive SYA by sacrificing the yield of one set of goals to attain the yield of another set

\section{Introduction}

Organizations exist to create value for their stakeholders that the stakeholders could not create for themselves as individuals. In recent decades, organizations have increasingly sought to create value using intellectual capital. In 2001, Alan Greenspan, head of the Federal Reserve Bank in the U.S.A., observed that "Over the last two decades, an ever increasing share of GDP has reflected the value of ideas more than material substance or manual labor input” (Greenspan, 2001).

Information Systems (IS) are implemented to increase an organization's ability to create value with intellectual capital. Information Systems are social systems that may or may not include an IT component (Land 1983, Mumford \& Wier 1979). The purpose of an information system is to provide decision makers with timely, accurate, and useful information with a minimum of cognitive load and financial cost. Organizations that seek to create value through their intellectual capital expect IS professionals to design and deploy information technology (IT) in ways that add value for stakeholders. A theoretical explanation of the mechanisms of value creation might make it easier for them to do so with less risk, and hence, more predictable success. Such a model might also be useful in domains other than IS/IT where value creation is of interest. 
IT implementation projects are the result of interaction among human beings who work towards attaining their own goals. Successful information systems are those that achieve change that is both feasible and desirable to its stakeholders (Checkland 1981). If organizations create value by efficient application of effort and resources (Hlupic \& Qureshi, 2003) then a model of value creation might make it possible to apply efforts and resources in ways that are most likely to give rise to value. This paper proposes such a model.

Studies of IT implementation suggest that that attitudes about the value technology can provide affect the quality of an IT implementation (Cragg and King 1993, Delone 1998). Winston and Dologite (2002) found that "high quality" IT implementations were associated with business owners who had either positive or negative attitudes towards IT, but not with owners who had uncertain attitudes. Thus, perceptions of value may be important to the success of IT implementation. A model of value creation might provide an understanding of the relationship between perceptions of value and IT Implementation success, and might suggest approaches for reducing the risk of IT implementation failures.

The more value an organization creates for its stakeholders, the more likely it is to survive. Organizations that cease creating value for stakeholders may cease to exist. The continuous restructuring of organizations suggests that in order to survive, organizations must continually adapt to the demands made on them by their stakeholders: customers, employees, stockholders and key constituents. Therefore, an understanding of the mechanisms of the human mind that give rise to judgments of value might be useful to those who design organizational processes and the systems that support those processes. Such an understanding might make it possible for them to sustain and increase the value an organization creates for its stakeholders.

The resource based view of the firm links firm performance to organizational resources and capabilities. Zhu and Kraemer (2002) suggest that in the IS literature, the resource based view has been used to explain how firms can create competitive value from IT assets, and how an organization's sustainability resides more in the skills used to leverage IT then in the technology itself. This suggests that for a technology implementation to be of value to an organization, its stakeholders should leverage resources and capabilities effectively. It appears that a causal model of value creation might make it possible to design and deploy technology in ways that are more likely to produce value for stakeholders.
Some authors suggest that value creation is related to technologies and processes. According to Por (2000) new technologies (such as collaboration tools) and new organizational paradigms are in a positive feedback loop that drives creation of new value. However, numerous IT implementation projects have failed to create the hoped-for value (Keil et al 1995, Keil 1999, Keil and Mann 1997). Research conducted into the business value of IT can be categorized into 1) the production based economics approach and 2) the process-oriented approach (Barua and Mukhopadhy 2000). The production based economics approach posits that lower prices for IT will bring about lower production costs for a given level of output. The process oriented approach attempts to explain the process through which IT investments improve intermediate operational performance, which in turn may affect higher levels of financial performance (Barua et al 1995). While certain technologies such as EDI may bring about significant cost savings and inventory reduction, other technologies such as internet based initiatives may induce large scale transformations within an organization as well as in its relationships with customers and suppliers (Zhu and Kraemer 2002). However, lower costs may not necessarily bring about competitive advantage for the organization (Brynjolfsson and Hitt 1998) because other organizations may produce products that customers value more highly, or may achieve the same cost savings through acquisition of similar technology.

An organizational stakeholder is a person whose wellbeing might be advanced by the choices made and actions taken by the people in an organization. Some stakeholders are members of an organization (e.g., employees, electees, inductees). Other stakeholders are people who are not members, but whose interests may be served by the organization (i.e., stockholders, customers, constituents). Mitroff (1985) suggests that stakeholders are the mind of the organization, interacting with each other to create states in which they may attain desirable outcomes. Locke and Latham (1988; 1990) define the construct, goal, as a desired state or outcome. The model posed in this paper posits that perceptions of value arise from cognitive mechanisms relating to goal attainment. Satisfaction Attainment Theory (SAT) (Briggs, Reinig, \& Vreede, 2003) suggests a set of cognitive mechanisms that would explain why perceptions of value arise in the human mind.

\section{Value Creation Concepts}

Perceptions of value have reference to some object-of-value. The term, object, in the context of this 
paper, means anything to which an individual could ascribe value - e.g., material goods, services (efforts), opportunities, states, ideas, or outcomes. The value of an object is defined in terms of its relative worth, utility, or importance compared to other objects. The value of an object is often characterized as the amount, as of goods, services, or money, considered to be a fair and suitable equivalent for something else; a fair price or return (American Heritage Dictionary of the English Language, 2000).

The concept of value can be understood in a number of overlapping senses. Whitaker (1904) distinguishes between a philosophical view, which concerns the ultimate nature, essence, and origin of value, and an empirical view, which pertains to the relation between value and observed exchanges. This paper posits that value originates in the mind of the individual through cognitive mechanisms relating to goal attainment. It seeks to explain the relation between value and observed exchanges.

Historically, economists have taken two major approaches to the question of the origins of value. One places the source of value in utility, the other in the expenditure of human effort, or labor (Bowman \& Amborsini, 2000). The utility of an object is the degree to which an individual derives or expects to derive benefit from an object. In the context of value creation, labor may be a surrogate for the broader concept of sacrifice, which is the yield an individual must forgo in order to attain an object. The model offered in this paper posits that both utility and sacrifice come into play in the cognitive mechanisms that give rise to perceptions of value.

Some economists argue that commercial organizations in a competitive environment create value by producing products more efficiently than do their competitors, or by using the same resources to create products that are more desired by consumers than are those of their competitors (e.g. Brynjolfsson and Hitt 1998). However, this perspective begins with the assumption that consumers already value the objects produced by an organization. A model of the cognitive mechanisms that give rise to perceptions of value might be useful to explain how and why those perceptions came to exist.

\section{The Approach of this Research}

From an interpretivist perspective, a theory is an ordered set of assertions about generic behaviors or structures assumed to hold throughout a significantly broad range of specific instances (Sutherland, 1975). From the interpretivist perspective, theories are derived by a process of disciplined imagination or sensemaking in which accurate representation may not be achieved but close correspondence of a particular description to the phenomenon being investigated shed valuable insight into the social world being investigated (Weick 2001). Interpretivist theories address questions of the meanings people impute to and the inferences they draw from the words and actions of others.

From a positivist perspective a theory is a nomothetic deductive model of cause-and-effect to predict or explain some phenomenon of interest (Popper, 1959). In the context of a positivist theory, the term, phenomenon of interest, refers to the effect that the theory attempts to explain. The domain of a theory is the context in which the effect manifests. The theory attempts to explain the causes of the effect in question. The theory itself is a model comprised of axioms and propositions. Axioms are assumptions about the nature of causal mechanisms relevant to the phenomenon of interest. Propositions, in this context, are functional statements of cause and effect, positing causal relationships among constructs. To be considered rigorous, a causal model of this kind must be internally consistent, such that its propositions logically follow from its assumptions. From the positivist perspective, causation does not necessarily imply determinism. Some causal relationships may be probabilistic rather than deterministic.

The argument in this paper takes a probabilistic positivist approach. The model proposed does not consider the construction of social reality through interaction among individuals. Rather, it proposes cognitive mechanisms which, during interactions among individuals, might give rise to perceptions of value. However, these perceptions might, in turn, be accepted and shared, and so become a socially-constructed reality in the interpretivist sense.

\section{Satisfaction Attainment Theory as a Model of Value Creation}

The Satisfaction Attainment Model (SAT) is a causal theory that was originally proposed to explain mechanisms that could give rise to satisfaction and dissatisfaction responses (Briggs, Reinig, and Vreede, 2003). The word, satisfaction, has at least two connotations in the English language: (a) a judgment that needs and constraints have been adequately addressed, and (b) an affective arousal associated with goal attainment. The phenomenon of interest that SAT originally sought to explain was the affective arousal associated with goal attainment. This paper argues that the cognitive mechanisms that give rise to satisfaction responses may also give rise to perceptions of value for 
an object, and that the satisfaction response is integral to perceptions of value.

Like satisfaction, perceptions of value may arise from the mechanisms of the mind that relate to goal attainment. A goal is a state or outcome that an individual desires to attain (Locke \& Latham, 1988). An individual holds multiple goals (Locke \& Latham 1990). An individual's goals may be diverse, ranging from the most basic biological needs - air, food, heat, etc., to esoteric abstractions like discovery and fulfillment. SAT begins with the assumption that:

Axiom 1. Purposeful Action. People act purposefully to attain goals. (Pinker, 2002)

Because people hold many goals, and because time and effort are limited, they must make choices about which goals to pursue and in what order. SAT posits mechanisms of the mind that may have evolved because people must make such choices. People hold goals because they expect to derive some utility from attaining the goal. SAT assumes an automatic mechanism of the mind that gives rise to those expectations:

Axiom 2. Goal Assessment: An individual automatically and subconsciously sets an expectation for some level of utility $\boldsymbol{U}_{\boldsymbol{G}}$ from attaining a given goal (Mobley \& Locke, 1970; Locke \& Latham, 1990.) and assesses the likelihood $\boldsymbol{L}_{\boldsymbol{G}}$ that a given goal will be attained (Vroom, 1964).

$\mathrm{L}_{\mathrm{G}}$ manifests as a level-of-certainty that a given goal will be attained. It can be represented as a probability with a range from zero to one. Thus, if Axiom 2 holds, an individual might expect some net yield from a given goal that would be the product of $\mathrm{U}_{\mathrm{G}}$ and $\mathrm{L}_{\mathrm{G}}$. If that were the case, then an individual might expect about the same yield for a high-utilitylow-likelihood goal as from a low-utility-highlikelihood goal. Further, if Axiom 2 holds, it must be that an individual's goals can be rank ordered in a hierarchy. For example one might expect more utility from attaining unrestricted access to breathable air than from attaining unrestricted access to a library of firstedition literary classics. If so, the breathing could be thought of as higher on the goal hierarchy than reading.

Some goals are mutually exclusive; the attainment of some sets of goals may preclude the attainment of others (Reinig, 2003). For example, attaining the goal of becoming a Catholic priest would preclude attaining the goal of marrying and raising a family. Therefore, in order to attain some sets of goals, an individual must be willing to sacrifice the attaining of some other sets of goals. SAT posits additional goal-related mechanisms that may be used to choose which goals to pursue and which to sacrifice.

Human attention resources are limited. Miller (1956) observed that people can only manipulate about seven plus-or-minus two concepts in working memory. Therefore, individuals may only aware of a subset of their goals at any given moment.

The goals that are in working memory or can be readily brought to mind are referred to as the Set of Salient Goals (SSG). At any given moment, the SSG may contain zero or one goal, or some combination of multiple goals, bounded by the limits of an individual's working memory. SAT assumes that:

Axiom 3. Yield Assessment for SSG: Individuals automatically and subconsciously make a yield assessment for their Set of Salient Goals $\mathbf{Y}_{\text {SSG }}$ that is an aggregation of the expectations of yield for the goals in the set.

Yield assessment (Y) manifests for the goal set as a whole, rather than separately for each separate goal in the salient set of goals. Axiom 3 can be summarized as follows:

Formula 1. $Y_{S S G}=f\left(\sum_{G}^{i=1} \mathrm{U}_{\mathrm{i}} \times \mathrm{L}_{\mathrm{i}}\right)$

Where:

$Y_{S S G}=$ Yield Assessment for the salient set of goals

$U_{i}=$ Utility expected from attaining Goal $i$

$\mathrm{Li}=$ Likelihood assessment for attaining Goal

$G=$ Number of goals in the salient set of goals

If $\mathrm{Y}, \mathrm{U}$, and $\mathrm{L}$ are all derived by automatic, subconscious mechanisms, then no deliberate effort would be required for an individual to derive them. But, by the same token because they are automatic and subconscious, the individual might be unaware of them. SAT posits a mechanism that might provide that awareness, when it assumes that:

Axiom 4: Affective Response to SYA. A perceived Shift in the Yield Assessment (SYA) for the salient set of goals is automatically accompanied by an affective arousal $\boldsymbol{R}$ proportional to the magnitude of the perceived shift and with a valence in the direction of the perceived shift.

If, as Axiom 4 posits, there is a cognitive capability that detects shifts in yield assessments, then 
that capability must include a mechanism that compares goal states. Thus, Axiom 4 could be summarized as follows:

Formula 2. $R_{t 2}=f\left(\sum_{j=1}^{m} L_{j} U_{j}-\sum_{i=1}^{n} L_{i} U_{i}\right)$

Where

t1 = A moment in time

t2 = A moment in time following $t 1$

$\mathrm{R}_{\mathrm{t} 2}=$ Affective arousal at time $t 2$

$m=$ number of goals in the Set of Salient Goals

at time $t 2$

$n=$ number of goals in the Set of Salient Goals at time 11

$L=$ Likelihood assessed for a given goal in a Set of Salient Goals

$U=$ Utility assessed for attaining a given goal in a Set of Salient Goals

The affective arousal $\mathbf{R}$ posited in Axiom 4 is the satisfaction response. If Axiom 4 holds, then, if individuals perceive that they are more likely to attain a goal, or that or that the goal, once attained, would yield more benefit, then they will feel a positive emotion. If the shift in yield assessment were small, then the affective arousal would be small, and might be labeled as satisfaction. If the change were great, then the emotion would be more intense, and might be labeled elation.

Contrariwise, if an individual perceives that they are less likely to attain a goal, or that the goal, once attained, will result in less utility, then the individual will feel a negative emotion. If the shift in expectation were small, then the affective arousal would be small, and might be labeled as dissatisfaction. If the shift were larger, then the affective arousal would be larger, and might be termed as frustration.

The affective arousal that accompanies an SYA event may serve as the alert mechanism from the subconscious mind to the conscious mind that something has changed with respect to yield assessments for salient goals. If the affective arousal is positive, it may signal that something has happened or is about to happen that advances one or more of an individual's goals. If the affective arousal is negative, it may signal that something has happened or is about to happen that may thwart an individual's goals. For high-salience goals, the conscious mind may be able to immediately to determine the goals for which the shift has occurred. If the mechanism that judges the yield of goal sets is subconscious, it is conceivable that, for lower-salience goals, affective arousal may manifest for some space of time before an individual becomes aware of which goals were affected by the shift.

If, as axiom 4 posits, a shift in yield assessment for the set of salient goals is accompanied by an affective arousal, that affective arousal may be one of the mechanism by which an individual judges the relative value of objects when contemplating their exchange. The yield of goals might be increased or actually attained by making the exchange, and yield for some goals might be sacrificed. As the person contemplates an exchange, the automatic goal evaluation mechanisms may detect whether the exchange would produce a net positive or net negative SYA. That should be accompanied by an affective arousal upon which the individual could base the choice of whether to make the contemplated exchange. If the individual would be likely to attain goals of great yield by making the exchange, and the goals sacrificed were unlikely to produce great yield, then the SYA invoked by contemplating the exchange should be significantly positive. So, for example, if one discovered a Rembrandt painting at a yard sale priced at \$65 USD, the aesthetic and financial benefits of acquiring the painting might vastly outstrip the yield that might result from using the $\$ 65$ in other ways. Therefore, a strongly positive SYA should give rise to a strongly positive affective arousal, which might, in turn, result in a strong inclination to make the exchange.

Conversely, if an individual contemplates an exchange involving the sacrifice of goals that were likely to produce high yield to attain goals that were likely to produce low yield, the SYA mechanism should produce a negative affective arousal, which might, in turn result in a strong disinclination to make the exchange. Thus, if Axiom 4 holds, it must be that:

Proposition 1. Perceptions of Value: The value of an object is a positive function of the SYA that occurs when an individual contemplates sacrificing the yield of other goals to obtain the yield that could be derived from the object.

The value of an object does not necessarily equal the utility it would provide to an individual. Rather, the value of an object can only be measured in terms of the yield of the goals an individual is willing to sacrifice to obtain the object. Consider the case of a very hungry traveler standing under the drooping boughs of an apple tree, surrounded by fruit just shaken from the tree by a gust of wind. A merchant approaches and offers to sell the traveler an apple. The 
hungry traveler could derive great benefit from the apple offered by the merchant. To buy the apple from the merchant, the traveler would have to forego the attainment of whatever other goals might have been attained by spending the money elsewhere. However, the traveler can attain the goal of assuaging hunger with apples without sacrificing any other goals, simply by reaching down and picking up a fresh apple from the grass at his feet. Therefore, the apple offered by the merchant would have no value to the traveler, even if it were $100 \%$ certain to provide substantial utility. must be that:

If Axiom 3 and Proposition 1 hold, then it

Proposition 2. Value Creation. Value is a positive function of the affective arousal that gives rise awareness of an opportunity to create a positive SYA by sacrificing the yield of some set of goals in order to attain the yield of another set.

If perceptions of value arise in response to an SYA, then it must be that value is created when an individual becomes aware of opportunities to obtain a positive SYA $_{\mathrm{SSG}}$ that can only be attained by sacrificing some set of goals to attain another set. If an individual becomes more aware of an opportunity for a positive SYA, value would come into existence. If the opportunity ceased to exist, value would be destroyed.

\section{Discussion}

One way to help determine whether SAT might be a useful model of value that IS professionals could use is to consider whether it can explain perceptions of value as they manifest in a variety of settings other than IS/IT.

\subsection{Cognitive Strategies for Value Creation}

If the logic of SAT holds then the value of an object is the yield from other goals that an individual is willing to sacrifice in order to obtain the object. Because yield has two components, benefit and likelihood, the sacrifice one makes to obtain an object might take two forms. One might forgo the benefit of a sacrificed goal. One might also accept a lower likelihood of attaining another goal in order to attain an object. Reducing the likelihood hood assessment reduces the net yield for a goal, and so constitutes a sacrifice. However, because an SYA manifests with respect to the entire set of salient goals, rather than with respect to separate goals within the set, there are four strategies for causing SYA that an IS professional may invoke:

1. Change the expectation of yield for one or more salient goals.

2. Change the assessment of the likelihood of attaining one or more salient goals.

3. Change the goals that comprise the current salient set of goals to goals for which higher yields are expected.

4. Change the time periods of the comparison of salient goal sets.

Note that these strategies can be applied not only to the yield to be obtained, but also to the yield to be sacrificed. Strategies One and Two create value by changing yield assessments by changing yield assessments for currently-salient goals. Strategies Three and Four create value by changing the focus of people's attention. Strategy Three derives from the limits of working memory; people who hold many goals cannot attend to all of them simultaneously. If a lower-yield goal is displaced in working memory by a higher-yield goal, the net effect is an upward shift in the overall yield assessment for the SSG. Psychologists, clergy, and entertainers all make use of this strategy to create value for their clients, sometimes focusing them, even if temporarily, on the goals they value more highly than those upon which they have been dwelling.

Strategy Four derives from the concept that shifts in yield assessments for goals, rather than actual goal attainment, drives the satisfaction response. If an individual fully expects to achieve a goal, and then does so, then no affective arousal would occur because assessed likelihood did not change (This might account for the anti-climactic nature of achievement-withoutrisk.)

\subsection{Value Creation In Organizations}

Although organizations exist only to create value for their stakeholders that the stakeholders could not create for themselves as individuals, it is important that decision makers and managers recognize that people often form organizations to achieve goals that none of the stakeholders wants. Consider, an example involving an automobile designer, a machinist, and a capitalist. Suppose that the designer had a heartfelt goal to achieve worldwide recognition and renown for her designs. Suppose that the machinist had a goal to achieve financial security for himself and his family. They might agree to form an organization to build automobiles. They might seek financing from the capitalist, who has a goal to increase his wealth. None 
of the actors in this organization wants an automobile. Indeed, none of them can achieve their goals until the organization gets rid of the automobiles, by exchanging them for money and sending them forth into the world.

If the principles in this organization agree that the name of the designer will appear on each automobile, and that the machinist will receive a bonus for each automobile sold, and that any profits above and beyond salaries and expenses will go to the capitalist, and if the customers like the automobiles well enough to buy them, then the organization is creating value for all its stakeholders, and so it can survive. On the other hand, should the capitalist decide that the name of the machinist should appear on each automobile, and that the designer should receive a bonus for each automobile sold, then the organization will not be creating value for two of its success-critical stakeholders. The machinist might conclude that the capitalist is a greedy evil-doer trying to cheat him by offering the meaningless name plaque that costs less than a dollar in lieu of granting him a meaningful bonus. The designer might conclude that the capitalist has stolen her ideas, giving her no credit, and is trying to buy her off with mere money. The organization would be at risk of failure. It is therefore critical for decision makers at all levels to continuously seek to discover the goals of success-critical stakeholders and to design processes such that stakeholders can attain their personal goals by helping the organization attain its declared goals.

\subsection{Mechanisms of Win-Win Exchange}

Exchanges of objects of value can be characterized as lose-lose, break even, win-lose, and win-win. If value were an inherent property of an object, then only zero-sum exchanges would be possible. Any benefit accrued by one party to an exchange would, of necessity, be a loss to another party. If each party's sacrifice were exactly offset by an attainment of equal yield, then the deal would be break-even. Otherwise, the exchange would be win-lose. The high proportion of amicable, pleasant relationships, however, suggests that most exchanges may be, in fact, win-win, where all parties to an exchange attain more yield than they sacrifice. This could occur when salient goals sets and yield assessments with respect to the objects exchanged differ across individuals. Consider again the example of the automobile company. The designer's salient goal set includes a high-yield goal for international recognition. The capitalist's goal set includes a high-yield goal for profit. Neither can attain their aims without the other, and neither can attain their aims without sacrifice. The designer judges that the sacrifice of time will produce a higher-yield result in recognition. The capitalist judges that the sacrifice of capital will produce a higher-yield result in profits. Thus, each values the yield attained higher than the yield sacrifice, and so the exchange is win-win.

\subsection{SAT and Affective Responses to Coercion}

Consider a scenario where a criminal gang extorts money from shopkeepers in a protection racket. The gangsters may hold a gun or a knife on the victim and threaten death unless monies are paid. The set of salient goals and the yield assessments for those goals shift very quickly for the victim in such a scenario. If the logic of SAT holds, then after the event, when goal states are no longer changing quickly, victims should feel a wide range of positive and negative affective responses as they compare the current more-or-less stable goal state to various goal-states that manifested during the coercive incident. When the shopkeeper compares the goal state before the gangsters arrived to the current goal state with lowered likelihood of attaining certain goals because less money is now available, a negative SYA should result in a negative affective arousal. By contrast, when the shop keeper compares the goal state of impending death to the current goal state, a positive SYA should produce a positive affective arousal. The wide range goal-state comparisons that are possible following a coercive incident may account for the flood of conflicting emotions reported by many victims following the incident.

\subsection{SAT and the Value of Entertainment}

To a lesser degree, these same dynamics that give rise to the mixed emotions of victims of coercion may also explain why people value sports, cinema, and other forms of entertainment. A sporting event presents both the participant and the spectator with a set of salient goals. The ebb and flow of the event create rapid swings in the likelihood that these goals will be attained.

So long as the goals of the game remain salient for the spectator, and so long as the spectator backs one team over another, the continuous shifts of goal-state during the game should result in continuous variations of affective arousal. During the game, such 
shifts might be far more intense and frequent than would routinely occur in daily life, yielding in a brief time affective responses that might otherwise be spread over months or years. If affective responses are one of the mechanisms people use to judge value, then the intensity of those responses might account for the value people attach to entertainment.

\subsection{Why Sex Sells}

SAT posits that affective arousal is one of the mechanisms that individual use to ascribe value to an object. It may be that a misattribution of arousal is the mechanism behind the maxim that "sex sells." The sight of a healthy, attractive person of the opposite sex who appears to be making eye-contact and who is exhibiting courtship behaviors tends to produce affective arousal. Research on arousal attribution suggests that humans may misattribute affective arousal given a salient and plausible decoy stimulus (Stultz 1984). Therefore, it may be that the affective arousal engendered by attractive models could be confused with the affective arousal engendered by a positive SYA from favorable goal-state comparisons. If that were the case, then sex would, indeed, sell.

\subsection{Implications for IS Professionals}

The mechanisms posited by SAT seem to explain perceptions of value in a wide range of circumstances. It may therefore be a useful model that IS professional can use to help guide their choices about how to design and deploy information systems.

There is an often repeated maxim among IS professionals that, ceteris paribus, people resist change. SAT suggests that the changes people resist are those that give rise to negative $\mathrm{SYA}_{\mathrm{SGA}}$ when they compare goal expected goal states after a change to expected goal states before the change. Because highlights the importance to system designers and developers of learning the goals of success-critical stakeholders. Because different individuals may have different goal hierarchies, it may not be sufficient to approximate the goals of classes of stakeholders. It may be important to learn the goals of the specific individuals whose acquiescence is required if the new system is to succeed.

The technology transition model (Briggs, et al, 1999) posits that people resist or adopt technology based on perceptions of value along a variety of dimensions - cognitive, political, social, physical, affective, and financial chief among them. Given that people hold this variety of goals, if people's goal hierarchies differ, and their sets of salient goals differ, then it may behoove IS professionals to adopt requirements elicitation practices that touch on all these dimensions, to reduce the risk that high-yield goals of success-critical stakeholders are not overlooked. Given that goal yield has two components - utility and likelihood, it is probably also useful to use elicitation techniques that consider both of those factors explicitly.

It is likely that success-critical stakeholders will hold conflicting goals. However, SAT posits that individuals cannot attend to all their goals simultaneously. If success-critical stakeholders were to come together to discuss their goals for a new system, it might be that hearing the goals of others would change the salience of some of their goals, and might change the composition of their salient set of goals. The result of these changes would be higher consensus than would otherwise be the case if stakeholders participated in a process where they only related their own goals without being made aware of the goals of others. Exposure to the goals of others might also make a stakeholder aware of higher-yield goals that had not heretofore been part of the SSG. Thus, it may be that a process that encourages interaction among stakeholders would result in higher consensus about the way forward, and might increase the likelihood that the solutions ultimately selected would accommodate high-yield goals for the stakeholders.

At deployment time, IS professional must obtain the cooperation of users and management for the new system to succeed. The four strategies for producing SYA might therefore be useful for persuading people to make the required changes. IS professional can point out opportunities for increases of utility and likelihood. They can find ways to change the goals to which the stakeholders are currently attending. They can also attempt change the time frame of goal state comparisons so stakeholders can perceive the opportunity for positive SYA, and so ascribe value to the change.

\subsection{Conclusions}

This paper offers Satisfaction Attainment Theory as a causal explanation for the cognitive mechanisms that give rise to perceptions of value. Those mechanisms may have evolved because people must sacrifice the yield of some goals to attain others, and these mechanisms may reduce the risks associated with making such exchanges.

On first analysis, this model seems to explain perceptions of value in a variety of settings. If its logic holds, it may be useful to IS professionals to help them decide how to devote time and resources in ways that 
are most likely to increase an organization's ability to create value for its stakeholders. However, much research remains to be done to determine whether the logic of this model will hold up to empirical scrutiny.

\subsection{References}

The American Heritage ${ }^{\circledR}$ Dictionary of the English Language, Fourth Edition. New York: Houghton Mifflin Company. 2000.

Barua, A. and T. Mukhopadhyay. Information Technology and Business Performance: Past, present and future.” In R. Zmud, ed. Framing the Domains of IT Management: Projecting the Future Through the Past. Pinnaflex Educational Resources, Cincinnati. 2000.

Barua, A., Kriebel, C.H. and T. Mukhopadhyay. Information Technology and Business Value: An Analytical and Empirical Investigation. Information Systems Research. 6(1). 3-23. 1995.

Bowman, C., \& Ambrosini, V. Value creation versus value capture: Towards a coherent definition of value in strategy. British Journal of Management, 11(1). 2000.

Briggs, R.O., Adkins, M., Mittleman, D., Kruse, J., Miller, S., \& Nunamaker, J.F., Jr. A Technology Transition Model Derived from Field Investigation of GSS use aboard U.S.S. CORONADO. Journal of Management Information Systems. 15(3), 151-193. 1999.

Briggs, R.O, Reinig, B. A., and Vreede, G.J. de. Satisfaction Attainment Theory and its Application To Group Support Systems Meeting Satisfaction. Information Science and Technology Working Paper Series, 1(1), College of Information Science and Technology, University of Nebraska at Omaha, 2003.

Brynjolfsson, E. and L. Hitt. Beyond the Productivity Paradox. Communications of the ACM. 41(8). 49-55. 1998.

Checkland, P. Systems Thinking Systems Practice. Wiley and Sons. Chichester. 1981.

Cragg, P.B. and M. King "Small firm Computing: Motivators and Inhibitors," MIS Quarterly, 17(1), 47-60. 1993.

Delone, W.H. Determinants of Success for Computer Usage in Small Business. MIS Quarterly, 12(1). 51-61. 1998.

Greenspan, A. Chairman of the Federal Reserve, in a speech to the National Association for Business Economics, as quoted in the New York Times, March 28, 2001.

Hlupic, V. and Qureshi, S. What causes value to be created when it did not exist before? A Research Model for Value Creation. Proceedings of the 36th
Hawai'i International Conference on System Sciences. IEEE., January 6 - 9, 2003

Keil, M., Truex, D.P., and Mixon, R., "The Effects of Sunk Cost and Project Completion on Information Technology Project Escalation," IEEE Transactions on Engineering Management, 42(4). 372-381, 1995.

Keil, M., "Pulling the Plug: Software Project Management and the Problem of Project Escalation," MIS Quarterly., 19(4). 421-447. 1999

Keil, M., and Mann, J., "The Nature and Extent of IT Project Escalation: Results From a Survey of IS Audit and Control Professionals (Part 1)," IS Audit and Control Journal, 1(1) 40-48, 1997.

Land, F. and R. Hirschheim. "Participative Systems Design". Journal of Applied Systems Analysis. 91-107. 1983.

Locke, E. A., Latham, G. P. and M. Erez. "Determinants of Goal Commitment". Academy of Management Review. 13(1) 23-39. 1988.

Locke, E.A., Latham, G.P. A Theory of Goal Setting and Task Performance, Englewood Cliffs, NJ: Prentice Hall. 1990.

Miller, G.A., (1956), The magical number seven, plus or minus two: Some limits on our capacity for processing information, Psychological Review, 63(1), 81-97.

Mitroff, J. Stakeholders of the Organizational Mind. San Francisco: Josey Bass. 1985.

Mobley, W.H., Locke, E.A. The relationship of value importance to satisfaction. Organizational Behavior and Human Performance, 463-483.

Mumford, E. and M. Weir. Computer Systems in Work Design: The ETHICS Method. New York: Wiley. 1979.

Pinker, S. The Blank Slate: The Modern Denial of Human Nature. New York: Viking Press, 2002.

Popper, K. The Logic of Scientific Discovery. New York: Routledge. 1959.

Por The Value of Emergent Value Creation 'models in the Knowledge Economy, Position paper presented to the European Commission's DirectorateGeneral Information Society, Brussels. May, 2000.

Reinig, B.A. Towards an understanding of satisfaction with the process and outcomes of teamwork. Journal of Management Information Systems, 19 (4). 2003.

Stultz, D.M., Messé, L.A., \& Kerr, N.L. Belief-discrepant behavior and the bogus pipeline: impression management or arousal attribution. Journal of Experimental Psychology. 20(1). 47-54. 1984. 
Sutherland, W.A.. Introduction to metric and topological spaces. Oxford University Press, Oxford, 1975.

Winston, E. R. and D. Dologite "How does Attitude Impact IT Implementation: A Study of Small Business Owners", Journal of End User Computing. Pp:16-29, April-June 2002.

Vroom, V.C. Work and Motivation. New York: Wiley, 1964.

Weick, K. E. Making Sense of the Organization. Oxford: Blackwell. 2001.

Whitaker, A.C. History and criticism of the Labor Theory of Value In English Political Economy. New York: Columbia University Press, 1904.

Zhu, K. and K. Kraemer. "eCommerce Metrics for net-Enhanced Organizations: Assessing the value of eCommerce to Firm Performance in the manufacturing Sector.” Information Systems Research. 13(3):275-295. 2002. 


\section{Publications in the Report Series Research* in Management}

\section{ERIM Research Program: "Business Processes, Logistics and Information Systems"}

\section{4}

Smart Pricing: Linking Pricing Decisions with Operational Insights

Moritz Fleischmann, Joseph M. Hall and David F. Pyke

ERS-2004-001-LIS

http://hdl.handle.net/1765/1114

Mobile operators as banks or vice-versa? and: the challenges of Mobile channels for banks

L-F Pau

ERS-2004-015-LIS

http://hdl.handle.net/1765/1163

Simulation-based solution of stochastic mathematical programs with complementarity constraints: Sample-path analysis S. Ilker Birbil, Gül Gürkan and Ovidiu Listeş ERS-2004-016-LIS

http://hdl.handle.net/1765/1164

Combining economic and social goals in the design of production systems by using ergonomics standards Jan Dul, Henk de Vries, Sandra Verschoof, Wietske Eveleens and Albert Feilzer

ERS-2004-020-LIS

http://hdl.handle.net/1765/1200

Factory Gate Pricing: An Analysis of the Dutch Retail Distribution

H.M. le Blanc, F. Cruijssen, H.A. Fleuren, M.B.M. de Koster

ERS-2004-023-LIS

http://hdl.handle.net/1765/1443

A Review Of Design And Control Of Automated Guided Vehicle Systems

Tuan Le-Anh and M.B.M. De Koster

ERS-2004-030-LIS

http://hdl.handle.net/1765/1323

Online Dispatching Rules For Vehicle-Based Internal Transport Systems

Tuan Le-Anh and M.B.M. De Koster

ERS-2004-031-LIS

http://hdl.handle.net/1765/1324

Generalized Fractional Programming With User Interaction

S.I. Birbil, J.B.G. Frenk and S. Zhang

ERS-2004-033-LIS

http://hdl.handle.net/1765/1325

\footnotetext{
* A complete overview of the ERIM Report Series Research in Management: https://ep.eur.nl/handle/1765/1

ERIM Research Programs:

LIS Business Processes, Logistics and Information Systems

ORG Organizing for Performance

MKT Marketing

F\&A Finance and Accounting

STR Strategy and Entrepreneurship
} 
Meta-heuristics for dynamic lot sizing: A review and comparison of solution approaches

Raf Jans and Zeger Degraeve

ERS-2004-042-LIS

http://hdl.handle.net/1765/1336

Reinventing Crew Scheduling At Netherlands Railways

Erwin Abbink, Matteo Fischetti, Leo Kroon, Gerrit Timmer And Michiel Vromans

ERS-2004-046-LIS

http://hdl.handle.net/1765/1427

Intense Collaboration In Globally Distributed Teams: Evolving Patterns Of Dependencies And Coordination

Kuldeep Kumar, Paul C. van Fenema and Mary Ann Von Glinow

ERS-2004-052-LIS

http://hdl.handle.net/1765/1446

The Value Of Information In Reverse Logistics

Michael E. Ketzenberg, Erwin van der Laan and Ruud H. Teunter

ERS-2004-053-LIS

http://hdl.handle.net/1765/1447

Cargo Revenue Management: Bid-Prices For A 0-1 Multi Knapsack Problem

Kevin Pak and Rommert Dekker

ERS-2004-055-LIS

http://hdl.handle.net/1765/1449

A Grounded Theory Analysis Of E-Collaboration Effects For Distributed Project Management

S. Qureshi, M. Liu and D. Vogel

ERS-2004-059-LIS

http://hdl.handle.net/1765/1448

A Phenomenological Exploration Of Adaptation In A Polycontextual Work Environment

P.C. van Fenema and S. Qureshi

ERS-2004-061-LIS

Satisfaction Attainment Theory As A Model For Value Creation

R.O. Briggs, S. Qureshi and B. Reining

ERS-2004-062-LIS 